\title{
Cleaner production implementation in a fruit juice production plant
}

\author{
Razuana Rahim, Abdul Aziz Abdul Raman*
}

Chemical Engineering Department, Faculty of Engineering, University of Malaya, 50603, Lembah Pantai, Kuala Lumpur, Malaysia

\section{A R T I C L E I N F O}

Article history:

Received 13 August 2014

Received in revisec

Accepted 23 March 2015

Available online 1 April 2015

\section{Keywords:}

Carbon dioxide emission

Fruit juice production

Cleaner production audit

Cleaner production options

\begin{abstract}
A B S T R A C T
This study was conducted to evaluate the feasibility of using Cleaner Production (CP) strategy in a fruit juice production plant. $\mathrm{CP}$ strategy is meant to reduce carbon dioxide $\left(\mathrm{CO}_{2}\right)$ emission by taking into consideration the economic, health and safety aspects. CP audit was conducted in the plant to quantify the total resources consumption and wastes generation from the production processes and activities in the plant. At the same time, areas for improvement in terms of resources consumption and productivity were also identified. The audit showed that the main contributors of $\mathrm{CO}_{2}$ emission of the plant were electricity, water and fuel consumption together with solid waste and wastewater generation. The analysis showed that the total $\mathrm{CO}_{2}$ emission generated at this plant was $0.07 \mathrm{~kg} \mathrm{CO}_{2}$ per litre of fruit juice, of which $88 \%$ was contributed by electricity consumption. Subsequently, six major CP options were generated and implementations of these options are expected to reduce the $\mathrm{CO}_{2}$ emission to $0.048 \mathrm{~kg}$ $\mathrm{CO}_{2}$ per litre of juice, a reduction of about $20 \%$ from its current emission. The estimated investment required for this reduction was 9455 USD with a payback period of 6 years. This study shows that CP strategy is potentially an economically feasible option to reduce $\mathrm{CO}_{2}$ emission of a fruit juice production plant.
\end{abstract}

(c) 2015 Elsevier Ltd. All rights reserved.

\section{Introduction}

In recent years, industrial activities have contributed significantly to Malaysian economic development. Malaysian economy was agricultural based in the 1970 s with rubber and palm oil as the main commodities (Rao, 2004). It then transformed into manufacturing-based in the 1980 s-1990s, primarily focussing on metal processing, food and paper production (Rao, 2004). Small and Medium Enterprises (SMEs) have been mushrooming since 2006 and according to the statistics by Census Report on Small and Medium Enterprises in 2011, there was a total of 645,136 registered Small and Medium Enterprises (SMEs) in Malaysia then, representing $97.3 \%$ of the total business establishments in the country. Among them, services and manufacturing sectors recorded the highest growth rates compared to the other sectors with the services sector having a growth rate of $90.1 \%$, followed by the manufacturing sector at $5.9 \%$. Construction, agriculture, and mining industry had a growth rate of $3 \%, 1 \%$ and $0.1 \%$ respectively in the same year (SME Annual Report, 2012). In terms of Gross Domestic Product (GDP) in 2011, contribution of SMEs increased to $32.5 \%$,

\footnotetext{
* Corresponding author. Tel.: +60 37967 5300; fax: +60 379675319

E-mail address: azizraman@um.edu.my (A.A.A. Raman).

compared to $29.4 \%$ in 2005 . Furthermore, the growth rate of SMEs $(6.8 \%)$ surpassed the overall economic growth (5.1\%) by $1.7 \%$ and this growth led to a marked employment rate of $6.4 \%$ and $6 \%$ of in SMEs and large firms, respectively in 2011. According to the statistics by Department of Statistics of Malaysia (DOSM), the number of employments in SMEs in 2011 was 3,669,259, out of which 698,713 were in the manufacturing sectors.

The demand for all types of beverage products in the market has increased significantly over the years and the beverage industry contributes to $15.8 \%$ of the manufacturing industry in Malaysia. The food-and-beverage industry normally operates at small and medium scale. In terms of manufacturing performance indicator, this industry is classified under Division 15 in Malaysian Standard Industrial Classification (MSIC) 2000 and was valued at USD 2.14 million in 2000 (Kamaruddin and Jusoff, 2009). In general, the beverage industry constitutes a diverse group of commodities ranging from bottled water to alcoholic drinks (Kourtis and Arvanitoyannis, 2001). The main subsectors of the beverage industry are soft drinks, malt, malt liquors and mineral beverages production. Besides, there is an increasing demand for exotic fruit juices or blends from grapefruit, pomegranate, cranberry, apple and orange, creating a base for more beverage production plants to establish.

The beverage industry has a less complex production system compared to food industry but it has a high consumption of raw 
materials, chemicals, water and energy, which results in high amount of waste and gaseous emission, posing significant risks to health and environment. Nguyen Ngoc and Schnitzer (2008) estimated that a mango juice production plant consumed approximately $0.136 \mathrm{kWh}$ of electricity, $0.02 \mathrm{~L}$ of fuel oil, and $20-25 \mathrm{~L}$ of water for every litre of juice produced, hence generating $10 \mathrm{~L}$ of wastewater and $350 \mathrm{~g}$ of solid wastes daily. Furthermore, a study by Madanhire and Mbohwa (2014) showed that a company that manufactured non-alcoholic beverages such as sparkling beverages, juices and nectars, fruit drinks and syrup drinks consumed $2 \mathrm{~L}$ of water and $0.11 \mathrm{kWh}$ of electricity, generating $3.4 \mathrm{~g}$ of solid waste and $0.5 \mathrm{~L}$ of wastewater for every litre of the beverage produced.

One of the main environmental concerns of a beverage production plant is the amount of untreated wastewater that contains high levels of biochemical oxygen demand (BOD) and chemical oxygen demand (COD), mainly generated from cleaning activities (Maxime et al., 2006); (Pap et al., 2004). Based on the environmental performance reports of different industries in 1997 by Department of Environment of Malaysia, the food-and-beverage industry was the main culprit of water pollution as the industry had the lowest compliance level with the relevant environmental regulations compared to the other industries. The report stated that the low compliance level was mainly attributed to absence of on-site wastewater treatment plants, poor maintenance of treatment systems or insufficient treatment capacity. Some researcher (El-Kamah et al., 2010) have therefore proposed wastewater treatment systems that are economically feasible and capable to improve the $\mathrm{COD}, \mathrm{BOD}_{5}$, total suspended solids (TSS) and oil and grease (O\&G) removal efficiency up to $97.5 \%, 99.2 \%, 94.5 \%$ and $98.9 \%$, accordingly from wastewater produced by fruit juice manufacturing plants. Apart from mechanical solutions, Nishijima et al. (2014 recommended green cleaning activities to substitute the conventional cleaning practices. For example, use of ozone instead of chemical cleaning agents can reduce organic deposits in wastewater eliminating the needs for post treatment of wastewater

Another important environmental issue associated with the beverage industry is high energy consumption, which is directly related to carbon dioxide $\left(\mathrm{CO}_{2}\right)$ emission. The beverage industry is recognized as one of the industries with intensive energy usage, apart from fabricated metal, chemical and textile industrie (Karakaya and Özilgen, 2011). $\mathrm{CO}_{2}$ emission from the beverage industry is contributed by fuel combustion, electricity usage and noncombustion activities, which involve heating, cooling, freezing, and other common processes (Mugwindiri et al., 2013). Besides, the mixing process in this industry is most of the time not optimally operated, resulting in excessive mixing time and motor capacity that are not necessary. A number of studies have indicated that $48 \%$ of the total electricity consumption in this industry are contributed by motors operations (Hasanuzzaman et al., 2011). Besides, it should also be noted that the capacity of motors is usually higher than the actual load requirement (Al-Mofleh et al., 2009). M.A Waheed (2008) estimated that the total energy consumption for processing 10 tonnes of orange juice was 11,196.5 MJ while the average energy intensity was $1.1 \mathrm{MJ} / \mathrm{kg}$. In his study, the most energy intensive operations were pasteurizing and packaging with an energy intensity of 0.9 and $0.1 \mathrm{MJ} / \mathrm{kg}$, respectively. Typically, the non-combustion emissions from a beverage manufacturing plant include hydrofluorocarbon (HFC) emissions from refrigeration, ai conditioning equipment and on-site wastewater treatment facility.

On top of that, the beverage production processes also generate high amount of solid waste, mainly from the rejected packaging materials, off-specification products and domestic wastes which may increase the load of treatment facilities and, indirectly result in high $\mathrm{CO}_{2}$ emission. Generation of a large volume of solid waste is normally inefficient waste management in the production plant where activities such as recycling, segregation and classification of wastes are not implemented. Pasqualino, Meneses, \& Castells (2011) who evaluated the environmental impact of manufacturing processes and disposal of the packaging materials for three beverage products (juice, beer and water) reported that $113 \mathrm{~g}$ of $\mathrm{CO}_{2}$ emission were generated for one life cycle of a 1-litre packaging bottle. They found that the amount of $\mathrm{CO}_{2}$ emission was directly proportional to the amount of waste packaging materials generated. Although the end-of-pipe treatment method appears to be the easiest strategy to manage wastes generated from production plants (Mohamed, 2009), such treatment normally involves cost such as operating cost of treatment facilities, chemicals and maintenance activities. Besides, end-of-pipe treatments are not the ultimate solutions for highly toxic or complex wastes where expensive advanced post treatment is needed. Consequently, SMEs are faced with challenges in sustaining the end-of-pipe treatment strategy due to financial constraints. Therefore, major efforts need to be taken to identify a sustainable strategy for waste management and reduction of $\mathrm{CO}_{2}$ emission from the beverage industry.

Statistics showed that Malaysia generated 151 million tons of $\mathrm{CO}_{2}$ emission from fuel combustion in industries alone in 2005 (Yow et al., 2011). The Prime Minister of Malaysia volunteered to reduce $40 \%$ of Malaysian $\mathrm{CO}_{2}$ intensity compared to that in 2005 by 2020 during the United Nations Climate Change Conference in Copenhagen in 2009. According to International Energy Statistics (2014), Malaysian $\mathrm{CO}_{2}$ intensity in 2005 was 1.07 metric tons/1000 USD. Hence, in order to achieve the 40\%-reduction target, Malaysia has taken several approaches in quantifying $\mathrm{CO}_{2}$ emission and outlining mitigation measures. There are many methodological approaches available in quantifying $\mathrm{CO}_{2}$ emissions (Dias and Arroja, 2012). According to Wiedmann \& Minx (2007), $\mathrm{CO}_{2}$ emission could be quantified using two main methodologies which were Process Analysis (PA) and Environmental Input-Output Analysis (EIO). The combination of PA and EIO produces a comprehensive strategy for $\mathrm{CO}_{2}$ emission quantification. PA focuses on identification of environmental impacts of products while EIO provides relevant analytical data for further studies on $\mathrm{CO}_{2}$ emission quantification. The Life Cycle Assessment (LCA) study by Becalli et al. (2009) reported that $1.0 \mathrm{~kg}$ of $\mathrm{CO}_{2}$ emission was generated from the production of 40 tonnes of natural orange juice while $6.0 \mathrm{~kg}$ of $\mathrm{CO}_{2}$ emission were generated from the production of 40 tonnes of concentrated orange juice. However, LCA study only identifies environmental impact, not mitigation strategies. A study by Lee and Rhee (2005) indicated that pollution preventive strategies result in a better environmental performance compared to end-of-pipe treatment approaches. Besides, prevention measures prove to be economically feasible with a short payback period and significan returns (Abou-Elela et al., 2008). Therefore, cleaner production (CP strategy, as a proven effective and economically viable approach for waste prevention and management for small-scale industries in developing countries (Hilson, 2000; Frijns and Van Vliet, 1999) has been adopted by the Malaysian government. CP strategy has been proven useful in improving the environmental performances of industrial processes through efficient use of raw materials, wate and energy which is associated with reduction of pollution and waste generation (Rao, 2004). It encourages sustainable development through process optimization, cost saving, higher business returns and higher compliance level with environmental regulations. Compared to end-of-pipe treatment methods, CP-based techniques and technologies focus on effective material, energy and by-products consumption to achieve the goals of reduced waste and hazardous materials generation. CP strategy makes waste management systematic and organised while promoting onsite and offsite reuse and recycling practices (Cagno et al., 2005). In addition, this strategy has significant contribution to 
environmental well-being at the global level as the ultimate goal of CP strategy is to reduce greenhouse gas (GHG) emissions, mainly global $\mathrm{CO}_{2}$ emission which is the main cause of climate change that affects global citizens. CP strategy can also be related to some standards that help in optimizing industrial processes. For example, Kourtis \& Arvanitoyannis, (2001) stated that strict adherence to quality (ISO 9001) and safety (Hazard Analysis and Critical Control Points, HACCP) management systems could eventually help the manufacturing industry operate with feasible operating costs while maintaining the stability and quality of final products, optimizing resources use and reducing waste generation.

Based on the literature review, there are limited case studies on implementation of CP strategies in the beverage industry, compared to food industry. Although the Malaysian government has taken great initiatives to encourage $\mathrm{CP}$ strategy implementation in SMEs, there is still limited information on $\mathrm{CO}_{2}$ emission from a beverage production plant. Recently, Department of Environment, Malaysia has developed a cleaner production implementation guideline specifically for the beverage industry. The guideline highlights the necessity of applying prevention strategies in reducing waste generation, material and energy loss, which are directly related to $\mathrm{CO}_{2}$ emission reduction. It consists of detailed implementation procedures of CP strategy with an emphasis on $\mathrm{CO}_{2}$ emission reduction, environmental quality and economic returns. However, the guideline only provides limited examples of case studies. Since there is a significant number of small-andmedium-scale beverage manufacturing plants in Malaysia, this study was conducted with the objective to demonstrate that $\mathrm{CP}$ strategy can help the beverage industry improve its environmental and economic performance. The study focuses on CP opportunities that can reduce $\mathrm{CO}_{2}$ emission in a fruit juice production plant in Malaysia by using real quantitative data. This study serves as a local case study for future literature reference since there are still a lot of research opportunities for this industry especially on organic waste management, according to Abidin et al. (2010).

This study covers four main steps of CP strategy: i) identifying resources consumption and emission; ii) auditing key procedures by applying $\mathrm{CP}$ auditing methodology to quantify $\mathrm{CO}_{2}$ emission; iii) proposing related $\mathrm{CP}$ options for resources saving and emission reduction; and iv) evaluating the feasibility of the suggested $\mathrm{CP}$ options in terms of environmental and economic benefits.

\section{Material and methodology}

This study adopted the CP methodology recommended by United Nations Environmental Programme and United Nations Industrial Development Organization (UNIDO/UNEP, 1991), which consists of sequential steps of planning, pre-auditing, detailed auditing, generation of potentials options, feasibility studies and evaluation. The feasibility of implementing CP strategy in a smalland-medium-scale fruit juice producing plant in Kuala Lumpur, Malaysia was studied. This company was established in 1991 and it had 45 workers at the time this study was conducted. It produced an average of $3456 \mathrm{~m}^{3}$ of 16 types of flavoured, concentrated and cordial juice annually. The company also had Hazard Analysis and Critical Control Points (HACCP) and Malaysian Islamic Dietary (HALAL) certificates. It was selected as the case study in this research due to its established operation and good record keeping system. Firstly, a preliminary site visit was conducted at the plant during which the company background information and process flowchart were obtained in order to have a clear understanding of the production processes, unit operation, onsite facilities and other activities in the plant. A walkthrough assessment was then conducted to observe the production processes and identify related activities and issues that can be further assessed during the detailed audit stage. The information obtained through preassessment was gathered and organized systematically. Such information was used in developing action plans for CP audit later and the process flow chart of the fruit juice manufacturing plant is presented in Fig. 1. The plant operated $8 \mathrm{~h}$ with 4 batches of productions daily. Generally, the production involved a 10 -step process. The main raw materials were assorted types of fruit puree imported mainly from India and the frozen ingredients were stored at $-10^{\circ} \mathrm{C}$ in a cold room up to three months. The frozen ingredients were thawed at room temperature before being mixed with dry ingredients which were then dispensed and batched according to the recipe. The formulated ingredients were dissolved separately in small-capacity mixing tanks before being pumped into a 3000-litre electrical mixing tank. The materials were then mixed homogenously with filtered water and liquid syrup for $1 \frac{1}{2}$ hours for each batch. The total amount of filtered water used as a raw material for the production was $108 \mathrm{~m}^{3}$ monthly. After the mixing, the produced juices were filled into 1-litre or 2-litre plastic packaging bottles, depending on the customers' requirement. They were then labelled, capped and packed accordingly. During the filling process, it was estimated that $2 \mathrm{~L}$ of products remained inside the filling hose, which was considered as a product loss. In addition, the production processes took place in a clean and hygienic fully airconditioned rooms at $16{ }^{\circ} \mathrm{C}$, which required significant electricity consumption. The finished products were stored at room temperature before delivery. All the manufacturing equipment, especially process tanks, were cleaned and rinsed by hot and cold water daily after production. It was also observed that wastewater from the cleaning activities was discharged without any pre-treatment.

A CP team membered by general manager and coordinators from Production, Quality and Research, and Administrative Department was formed. They were selected as they could assist in the overall implementation of CP strategy in the plant. Information and data were collected by reviewing the material and utility purchase records, interviews with plant coordinators, and measurement of input and output streams. A detailed CP audit was conducted for the entire production processes to obtain the qualitative and quantitative information of resources consumption, wastes generation, emissions, and $\mathrm{CO}_{2}$ emission per unit of juice produced ( $\mathrm{kg} \mathrm{CO}_{2}$ /litre juice produced). The information obtained was used to generate $\mathrm{CP}$ options for reducing $\mathrm{CO}_{2}$ emission and the overall production cost. A brainstorming session was held to gather ideas suggested by plant coordinators and operators. Subsequently, environmental and economic feasibility studies were performed to prioritize the most feasible and beneficial options. However, since small-and-medium-scale companies have very limited financial resources and capabilities, the proposed CP opportunities must therefore be economically reasonable and affordable (Schollenberger et al., 2008).

During the audit, the production processes were analysed in detailed and translated into a process diagram showing the input and output of resources (raw materials, water, energy) and waste flows, at each step of the production process. This diagram clearly shows the types of resources consumed, types of waste generated and the sources of loss and waste generation in the production processes. Detailed quantification of resources and wastes served as the basis for generation of CP options. Water used by the plant was supplied by Syarikat Bekalan Air Selangor, Malaysia and was pretreated before being used in the production processes. The plant only has one water metre at the entrance of the plant and so the total amount of water consumed was quantified based on the volume stated in the monthly bills. The water consumption in the plant was divided into two categories, which were 'process water' and 'nonprocess water'. 'Process water' was initially filtered before being used as the raw material ingredient, while 'non-process water' referred to 


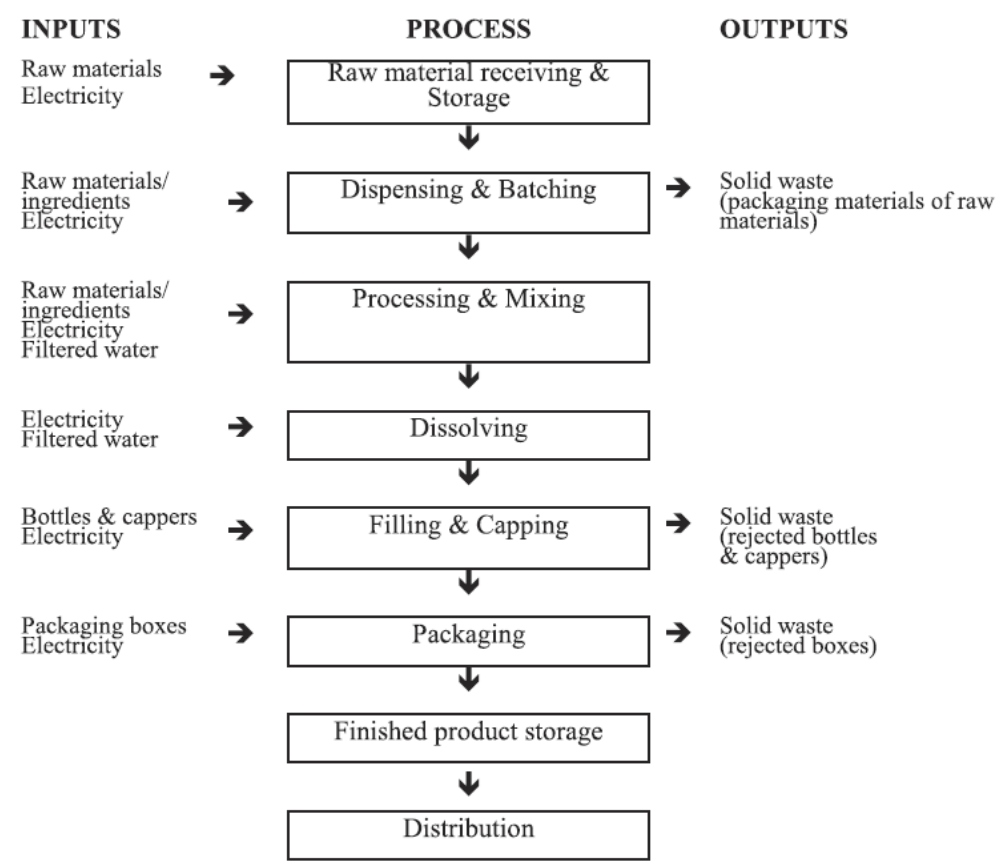

Fig. 1. Fruit juice manufacturing process flow diagram.

water used for cleaning activities (Clean In Place) and domestic purpose. The volume of process water was obtained directly from the product recipe. However, it was assumed that the volume of nonprocess water equalled to the discharged wastewater. Hence, the water consumption was quantified using Equation (1):

Total water consumption $\left(\mathrm{m}^{3} /\right.$ month $)=$ process water $+($ water for cleaning activities + water for domestic purpose)

In addition, the COD level of a sample of wastewater was analysed to determine raw material loss and pollution load to the environment, as suggested by Amuda et al. (2006). Quantification of total electricity consumption was done based on the monthly bills received from the electricity supply company. The main unit operations of the plant together with the respective energy rating and daily operating hours were identified in order to get a detailed breakdown of the electricity consumption. However, the tota number and energy ratings of auxiliary appliances such as lightings, computers and air conditioning were manually calculated on-site The electricity consumption was calculated using Equation (2):

Electricity consumption $(k W h /$ month $)=$ electrical rating $(k W) x$ (operating hours/day) $x$ (no. of unit operation or appliance) $x$ (no. of working day/month)

The plant consumed fuel for forklifts operations only. Therefore, fuel consumption was quantified based on the monthly record of fue purchase, where the total price of fuel was translated into amount of fuel in kilogramme. Furthermore, the raw materials receiving area, storage area, packaging area, research and quality laboratory, administration office and product processing area were assessed to identify losses and wastes. Each production process was assessed to identify activities that caused materials loss through spillage or disposal. Solid waste mainly comprises of packaging materials, including raw material packaging drums, containers, and rejected packaging bottles. The generated solid waste was stored in specific areas before being collected by the waste contractors. The amount of solid waste generated in the plant was quantified based on the waste contractor's bills for solid waste collection. In addition, the monthly domestic waste generated from the administration office, which were mainly printed papers and drinking water bottles were collected and weighed before being sent for recycling activities. 6 month data were used for the measurement to account for the cyclic pattern of the production rate variation of the production plant.

Data analysis was the final step in CP assessment to determine the targeted entity or area for improvement and to quantify $\mathrm{CO}_{2}$ emission generated from the overall production processes in the plant. The suggested $\mathrm{CP}$ options, together with their estimated economic returns and $\mathrm{CO}_{2}$ emission reduction were discussed in detail in the next section. Based on the audit findings, the $\mathrm{CO}_{2}$ emission of the studied plant, quantified by evaluating five entities (consumption rate of water, electricity, fuel, generation rate of wastewater and solid waste) was set within the boundary of gateto-gate production. The $\mathrm{CO}_{2}$ emission was quantified using the factor-based approach according to Intergovernmental Panel of Climate Change (IPCC) method, which has been developed to estimate GHG emission for major economic sectors (Vergé et al., 2013). Based on the methodology, $\mathrm{CO}_{2}$ emission of an entity is calculated by multiplying the entity data (e.g., $\mathrm{m}^{3}$ of water consumed) by the emission factor for that entity (e.g., $\mathrm{kg} \mathrm{CO} / \mathrm{m}^{3}$ water). The total $\mathrm{CO}_{2}$ emission is calculated by summing the

\section{Link to Full-Text Articles :}

http://ac.els-cdn.com/S0959652615002966/1-s2.0-S0959652615002966-main.pdf? tid=f0226c90-400f-11e5945a-00000aacb361\&acdnat $=1439287470 \_18 e 31$ ba5d810028e2fb9f30eca23f341 